\title{
Increased cholecystectomy rate after the introduction of laparoscopic cholecystectomy in Scotland
}

\author{
Chi-Ming Lam, F E Murray, A Cuschieri
}

\begin{abstract}
This survey determined the effect of the introduction of laparoscopic cholecystectomy on the rates of cholecystectomy (total and laparoscopic) in Scotland. From 1977 to 1990 , the Scottish cholecystectomy rate fell by an average of almost $1 \%$ per annum. With the advent of laparoscopic cholecystectomy, the total cholecystectomy rate (open and laparoscopic) rose considerably - by 18.7\% from 1989-93 (p<0.05). The largest increase $(25 \%)$ was observed in the 45-64 years age group but it was also particularly evident $(19 \%)$ in elderly patients (65-74 years). Subjects were more likely to undergo laparoscopic cholecystectomy than open cholecystectomy if they were young and female. The increased cholecystectomy rate observed merits careful scrutiny and health economic evaluation. (Gut 1996; 38: 282-284)
\end{abstract}

Keywords: laparoscopic cholecystectomy, cholecystectomy rate.

The Departments of Surgery and Clinical Pharmacology, Ninewells Hospital and Medical School, University of Dundee C-M Lam

F E Murray

A Cuschieri

Correspondence to: Dr F Murray, Department of Clinical Pharmacology, Ninewells Hospital and Medical School, Dundee DD1 9SY.

Accepted for publication 15 August 1995

Laparoscopic cholecystectomy (LC) seems to be a less expensive ${ }^{1-3}$ and safer $^{3-4}$ procedure than open cholecystectomy. Estimated health economic gains from its introduction, however, may be altered if the indications for the operation change. Evidence from other countries suggests that this may be the case. The total cholecystectomy rates in two states in the USA have increased since the introduction of LC, with estimates of the increase varying from $28-60 \% .{ }^{5-7}$ Similar trends have also been reported in Canada (17.4\%) and Australia $(26 \%){ }^{8}$ The reasons for this apparent

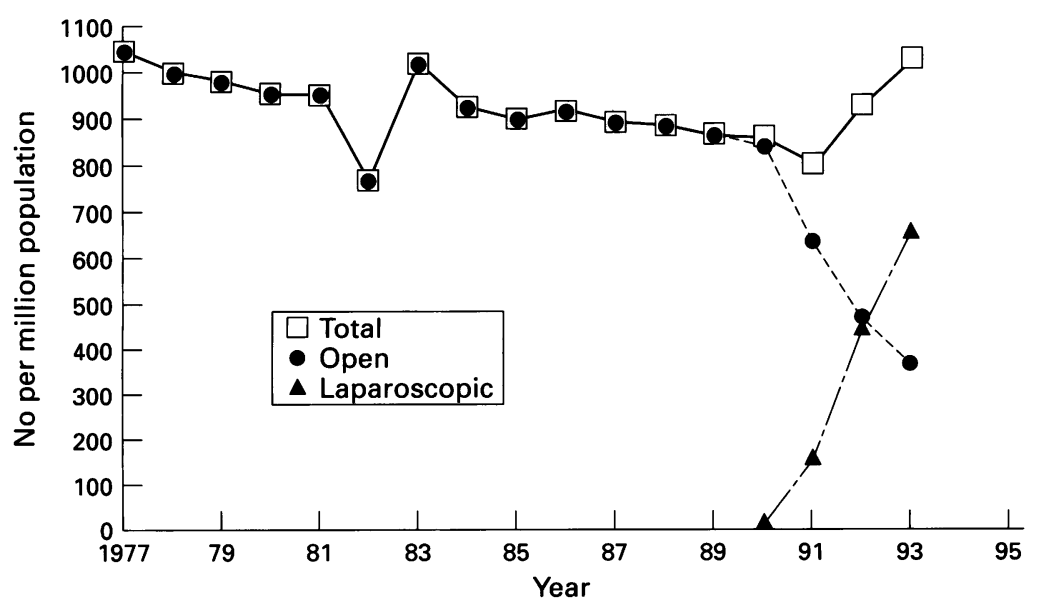

Figure 1: Cholecystectomy rate in Scotland, 1977-93. worldwide change are not known. The increased cholecystectomy rate may reflect a lowered surgical threshold but other factors may be operative. Whatever the reason, and despite the established cost benefit of LC over the open procedure, ${ }^{2910}$ there are important implications for health service expenditure if the reported increase in the cholecystectomy rate reflects the true situation. For this reason we surveyed the effect of the introduction of LC on the cholecystectomy rate in Scotland, where accurate data for operative treatment within the NHS are available and the population has been stable for several decades.

\section{Methods}

SOURCE OF DATA

The data were obtained for the Information and Statistics Division of the National Health Service in Scotland. NHS hospitals in Scotland are obliged to report their operation statistics, specifying the type and number of operations performed. These data are coded by the OPCS system (Classification of Surgical Operations, The Office of Population Censuses and Surveys), and published by the Scottish Health Office annually.

\section{CHOLECYSTECTOMY RATES}

Open cholecystectomy was recorded as OPCS3 code 522 or OPCS 4 code of J18, without pairing with J08.8 (other specified therapeutic endoscopic operations on liver using laparoscope) or Y50.8 (other specified approach through abdominal cavity). LC was identified as OPCS-4 codes of J18, paired with J08.8 or Y50.8. The cholecystectomy rate was calculated according to the population data published by the Registrar General for Scotland. The cholecystectomy rate of each age group was based on the population of that age group at the time of recording.

STATISTICS

In the analysis, differences across years or across age groups were compared using a test of trend $\chi^{2}$ statistics.

\section{Results}

TOTAL CHOLECYSTECTOMY RATE IN SCOTLAND Between 1977 and 1990, the total cholecystectomy rate fell from its peak in 1977 (1044.7 per 


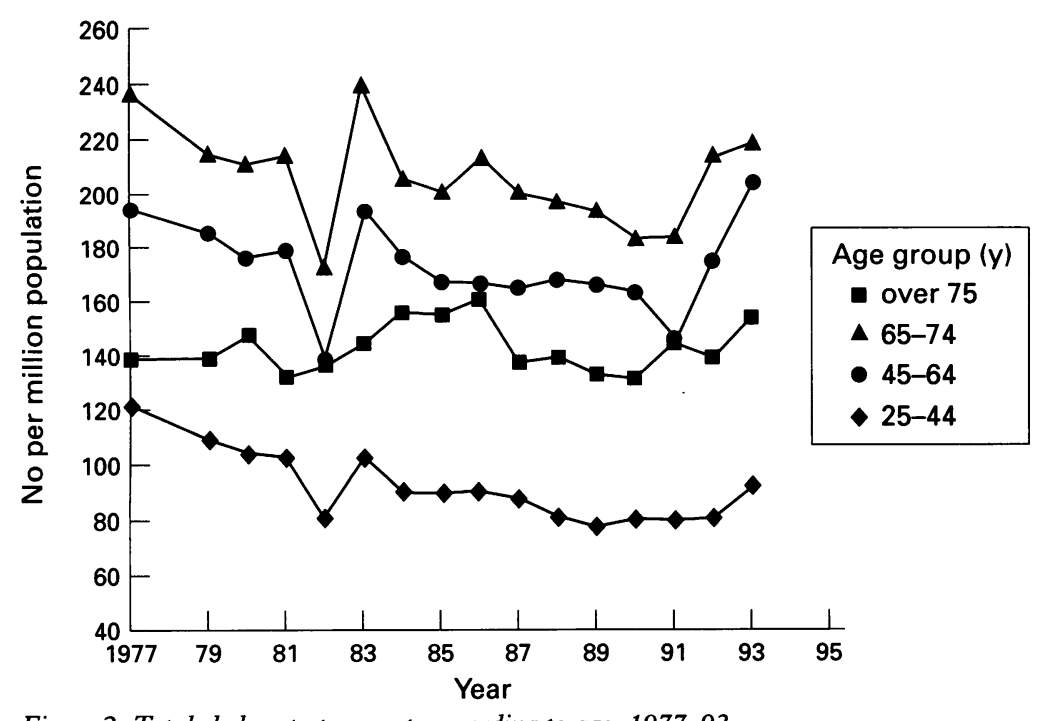

Figure 2: Total cholecystectomy rate according to age, 1977-93.

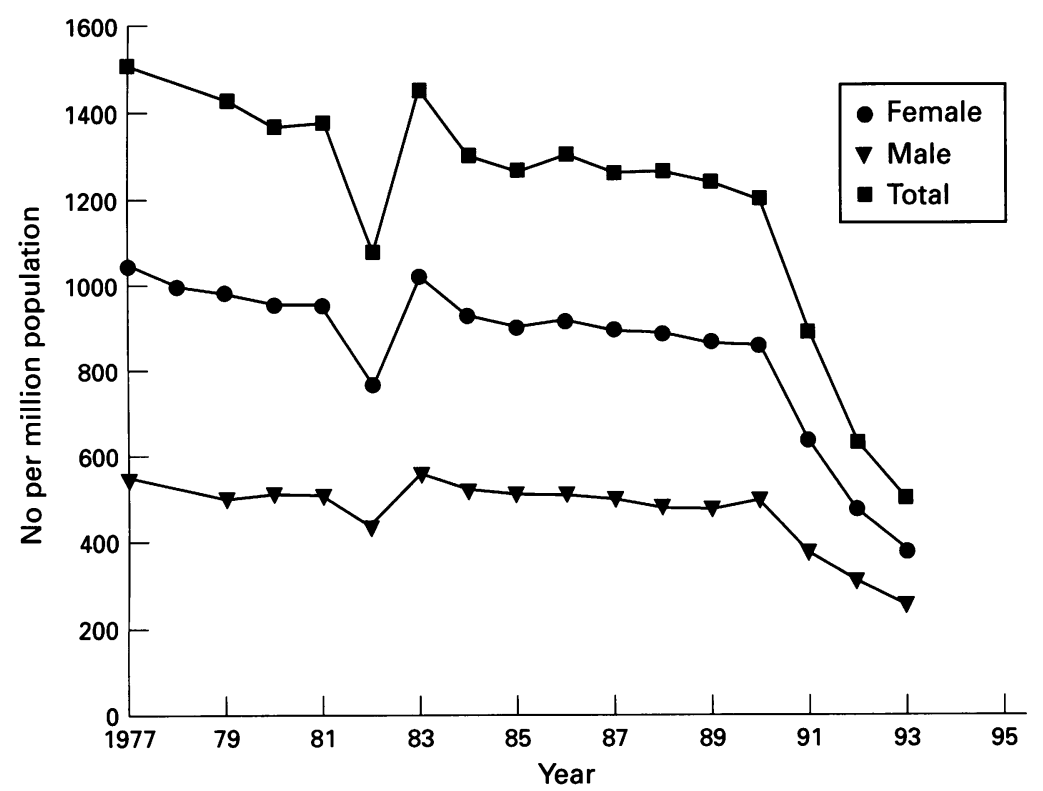

Figure 3: Open cholecystectomy rates for both sexes, 1977-93.

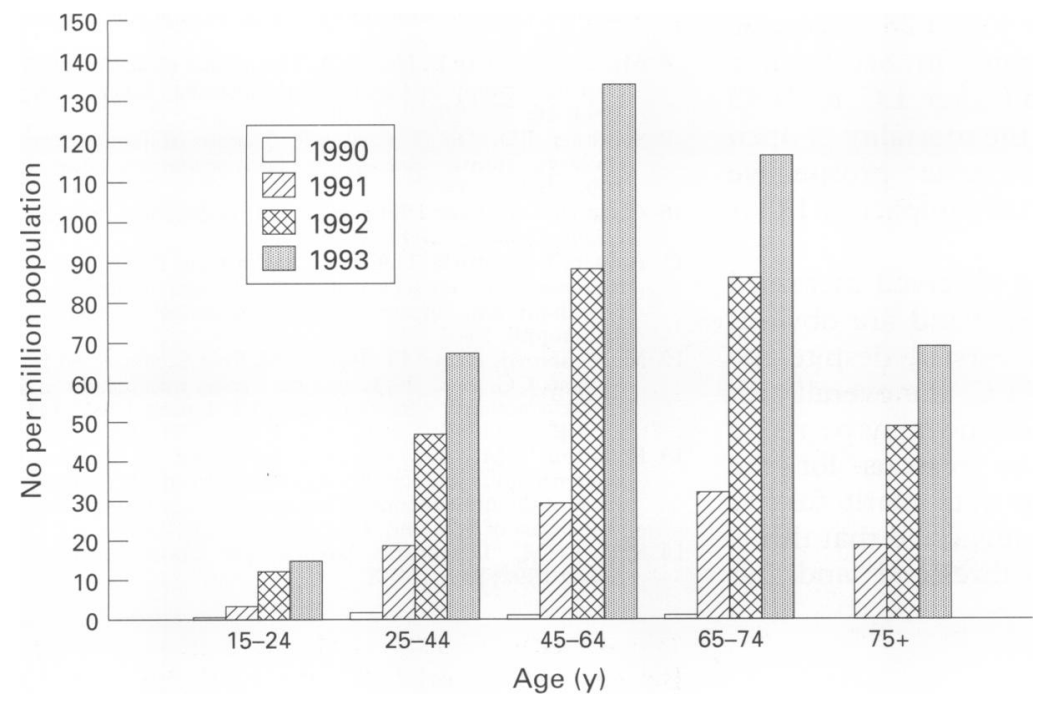

Figure 4: Laparoscopic cholecystectomy rate in age bands. million population) at a rate of about $1 \%$ per annum (Fig 1). Thus, compared with 1977, the cholecystectomy rate had decreased by $17.0 \%$ in 1990 . With the introduction of LC in 1989 , the total cholecystectomy rate has risen significantly $(\mathrm{p}<0.05)$, and by $1993 \mathrm{had}$ almost returned to its peak in 1977 (1028.4 per million population). The increase in the total cholecystectomy rate during this period was observed in all the age groups, although the greatest increase was noted in the 45-64 years $(25 \%)$ and the $65-74$ years $(19 \%)$ groups (Fig 2 ) and was similar in both sexes.

\section{OPEN CHOLECYSTECTOMY RATE}

The rate of open cholecystectomy fell dramatically by $58 \%$ between 1989 and 1993 $(p<0.005)$ (Fig 3). This change was observed in both sexes and all age groups.

\section{LAPAROSCOPIC CHOLECYSTECTOMY}

From 1989 onwards, the LC rate increased considerably and in 1993, $64 \%$ of all cholecystectomies were performed via the laparoscopic approach (Fig 1). The LC rate in the different age groups is shown in Figure 4 . The highest LC rates were observed in the 45-64 years and 65-74 years age groups. The number of $\mathrm{LC}$ as a percentage of the total number of cholecystectomies for the various age groups is shown in Table I. These data indicate that the likelihood of cholecystectomy being performed laparoscopically was highest in the youngest age group, and this fell significantly with age. Thus, subjects aged 25-44 years undergoing cholecystectomy were $50 \%$ more likely to be treated by LC than those aged 75 years or more.

Females were more likely to have cholecystectomy performed laparoscopically than males (Table II). The female to male ratio for cholecystectomy in the past 10 years (1980-89) before LC had been fairly constant at $2 \cdot 5$ to $2 \cdot 7: 1$.

\section{Discussion}

This survey aimed to analyse alterations in the cholecystectomy rate in Scotland since this country is well placed for such an evaluation with structured and complete data on hospital based surgical procedures and a relatively stable population. Furthermore, most patients in Scotland are treated in NHS hospitals. Thus, the data on which this survey was based are likely to be reliable and comprehensive.

The total cholecystectomy rate in Scotland fell at a rate of about $1 \%$ per annum since 1977. The cause for this is not clear, although a similar trend has been noted in Sweden. ${ }^{11}$ The statistically significant increase in the cholecystectomy rate with the advent of LC in Scotland observed in this survey is of a similar magnitude to that reported in Maryland, Canada, and Australia but lower than in reports from Connecticut. ${ }^{5-8}$ Only one previous study from Maryland had reported on the age factor. ${ }^{7}$ In agreement with the findings 
TABLE I Laparoscopic cholecystectomies expressed as a percentage of the total number of cholecystectomies in Scotland, 1990-93

\begin{tabular}{|c|c|c|c|c|c|c|}
\hline \multirow[b]{2}{*}{ Year } & \multicolumn{5}{|c|}{ Age group (y) } & \multirow[b]{2}{*}{ p Value ${ }^{\star}$} \\
\hline & $15-24$ & $25-44$ & $45-64$ & $65-74$ & $75+$ & \\
\hline $\begin{array}{l}1990 \\
1991 \\
1992 \\
1993\end{array}$ & $\begin{array}{r}2 \cdot 8 \\
21 \cdot 4 \\
62 \cdot 2 \\
75 \cdot 5\end{array}$ & $\begin{array}{r}1.9 \\
23 \cdot 9 \\
57 \cdot 9 \\
72 \cdot 6\end{array}$ & $\begin{array}{r}0.5 \\
20 \cdot 2 \\
50 \cdot 5 \\
65 \cdot 5\end{array}$ & $\begin{array}{r}0 \cdot 5 \\
17 \cdot 6 \\
40 \cdot 2 \\
53 \cdot 2\end{array}$ & $\begin{array}{r}0 \cdot 2 \\
13 \cdot 1 \\
35 \cdot 0 \\
44 \cdot 7\end{array}$ & $\begin{array}{l}<0.05 \\
<0.05 \\
<0.005 \\
<0.005\end{array}$ \\
\hline
\end{tabular}

${ }^{\star} p$ Value of the increasing trend of laparoscopic

cholecystectomy performed in younger age groups.

of the present study, the Maryland group observed that patients undergoing LC were younger by an average of four years than those treated by open cholecystectomy. ${ }^{7}$ Why LC has become the predominant surgical treatment in young females with symptomatic gall stone disease is understandable and probably reflects a cosmetic preference and a reduced prevalence of ductal calculi when compared with older patients of either sex.

Although most investigators reported a decrease in the unit cost of LC, a recent randomised trial found a $36 \%$ increase in the unit cost of LC compared with open cholecystectomy. ${ }^{12}$ This latter trial recruited 151 patients from five hospitals. An average distribution of only 30 patients in each hospital may increase the cost of laparoscopic equipment in each operation. Furthermore, the use of disposable laparoscopic equipment also increases the cost tremendously. Even if the unit cost of LC falls, the total cost may increase because of the increase in the number of operations. Legoretta et $a l^{5}$ have calculated that the total costs of cholecystectomy in Connecticut have increased by $11 \%$ since the introduction of LC despite the lower unit costs of this procedure compared with open cholecystectomy.

Although there have been retrospective data suggesting a reduced mortality after LC compared with open cholecystectomy, the total number of deaths following cholecystectomy may not be reduced due to the increased number of operations being performed. Thus, although Steiner et $a l^{7}$ reported a drop in the postoperative mortality rate of $33 \%$ after the introduction of LC in Maryland, the total number of postcholecystectomy deaths in this state has not changed due to the $28 \%$ increase in the cholecystectomy rate. In Scotland, a $0.5 \%$ mortality was found after LC in 1683 patients: this is similar to the mortality of open cholecystectomy in the same prospective study. ${ }^{13}$ Thus the health care impact of LC is unclear.

The implications of the observed increased cholecystectomy rate in Scotland are obvious for at least two reasons. Firstly, despite the enhanced cost efficacy of LC, the overall cost of cholecystectomy in Scotland may be rising quickly. Furthermore, the reasons for the increased cholecystectomy rate merit further investigation. It has been suggested that this is due to a reduced surgical threshold ${ }^{1}$ and that
TABLE II The female to male ratio of patients undergoing laparoscopic and open cholecystectomy

\begin{tabular}{lll}
\hline \multirow{3}{*}{ Year } & Female to male ratios \\
\cline { 2 - 3 } & Laparoscopic cholecystectomy & Open cholecystectomy \\
\hline 1990 & $2 \cdot 5: 1$ & $2 \cdot 4: 1$ \\
1991 & $3 \cdot 2: 1$ & $2 \cdot 4: 1$ \\
1992 & $3 \cdot 3: 1$ & $2 \cdot 0: 1$ \\
1993 & $3 \cdot 7: 1$ & $2 \cdot 0: 1$ \\
\hline
\end{tabular}

surgeons may be treating asymptomatic gall stone disease or resorting to LC as a 'diagnostic therapeutic test' ${ }^{14}$ It is difficult to accept this explanation for Scotland without any material evidence that patients with asymptomatic gall stone disease are being subjected to LC. There are other possible explanations, and these must all be considered in future health service studies on this problem. These include increased referral by general practitioners and gastroenterologists resulting from the enhanced perceived benefits of LC, diminished recourse to alternative non-surgical therapy (extracorporeal lithotripsy and oral bile salt therapy), increased patient acceptability so that few patients refuse surgical treatment, etc. Regrettably data on these factors, which may or may not be operative in accounting for the increased cholecystectomy rate in Scotland, are not available.

We thank Mr David Murphy, Statistical Support Manager of the Information \& Statistics Division NHS Scotland, for his help in providing cholecystectomy data.

1 Fullarton GM, Darling K, Williams J, MacMillan R, Bell G. Evaluation of the cost of laparoscopic and open cholecystectomy. Br F Surg 1994; 81: 124-6.

2 Bass EB, Pitt HA, Lillemeo KD. Cost-effectiveness of laparoscopic cholecystectomy versus open cholecystectomy. Am ₹ Surg 1993; 165: 466-71.

3 Peters JH, Ellison EC, Innes JT, Liss JL, Nichols KE Lomano JM, Roby SR, Front ME, Carey LC. Safety and efficacy of laparoscopic cholecystectomy - A prospective efficacy of laparoscopic cholecystectomy - A prospective analysis

4 Wilson RG, Macintyre IMC, Nixon SJ, Saunders JH, Varma JS, King PM. Laparoscopic cholecystectomy as a safe and effective treatment for severe acute cholecystitis BMF 1992; 305: 394-6.

5 Legoretta AP, Silber JH, Constantino GN, Kobylinski RW, Zata SL. Increased cholecystectomy rate after the introduction of laparoscopic cholecystectomy. $\mathscr{f} A M A$ 1993; 270: 1429-32.

6 Orlando R, Russell JC, Lynch J, Mattie A. Laparoscopic cholecystectomy, a statewide experience. Arch Surg 1993, 128: 494-9.

7 Steiner CA, Bass EB, Talamini MA, Pitt HA, Steinberg EP. Surgical rates and operative mortality for open and laparo-
scopic cholecystectomy in Maryland. $N$ Engl $\mathcal{F}$ Med 1994; 330: 403-8.

8 Marshall D, Clark E, Hailey D. The impact of laparoscopic cholecystectomy in Canada and Australia. Health Policy 1994; 26: 221-30.

9 Schrimer BD, Dix J. Cost effectiveness of laparoscopic cholecystectomy. Fournal of Laparoendoscopic Surgery 1992; 2: 145-50

10 Cuschieri A. Cost-effectiveness of endoscopic surgery. Health Economics 1993; 2: 367-9.

11 Ahlberg J, Ewerth S, Hellers G, Holmstrom B. Decreasing frequency of cholecystectomies in the counties of Sequelm and Uppsala, Sweden. Acta Chir Scand 1978; 482 (suppl): 21-3.

12 McMahon AJ, Russel IT, Baxter JN, Ross S, Anderson JR, Morran CG, et al. Laparoscopic versus minilaparotomy Morran CG, et al. Laparoscopic versus minilaparotomy cholecystec

13 Fullarton GM, Bell G, and the West of Scotland Laparoscopic Cholecystectomy Audi Group. Prospective audit of the introduction of laparoscopic cholecystectomy in the west of Scotland. Gut 1994; 35: 1121-6.

14 Spiro HM. Diagnostic laparoscopic cholecystectomy Lancet 1992; 339: 167-8. 